\title{
Comparative Evaluation of Different Obturation Techniques in Primary Molars Pulpectomy: A Clinical Study
}

\section{Hanaa Mahmoud Shalan ${ }^{1 *}$, Salwa M. Awad ${ }^{2}$, Ahmed H. Wahba ${ }^{3}$ and Hamada Bakr Mohamed ${ }^{4}$}

${ }^{1}$ Pediatric Dentistry Department, Faculty of Dentistry, Mansoura University, and Badr University in Cairo (BUC), Egypt

${ }^{2}$ Professor of Pediatric Dentistry, Faculty of Dentistry, Mansoura University, Egypt ${ }^{3}$ Lecturer of Pediatric Dentistry, Faculty of Dentistry, Mansoura University, Egypt ${ }^{4}$ Mansoura University, Dentist at Ministry of Health , Egypt

*Corresponding Author: Hanaa Mahmoud Shalan, Pediatric Dentistry Department, Faculty of Dentistry, Mansoura University, and Badr University in Cairo (BUC), Egypt.

DOI: $10.31080 /$ ASDS.2022.06.1313
Received: January 11, 2022

Published: February 10, 2022

C All rights are reserved by Hanaa Mahmoud Shalan.

\begin{abstract}
Introduction: Extensive dental caries in primary dentition, remains a serious problem in pediatric dental practice.

Objective: To evaluate different obturation techniques of pulpectomized primary molars using pressure syringe (Map System), endodontic plugger and rotary lentulo spiral

Methodology: The clinical study was carried out on 120 pulpectomized primary molars, which divided into two groups according to the material used for obturation. Group I: obturated with zinc oxide eugenol paste (ZOE). Group 2: obturated with Iodoform paste. According to obturation technique, each group was subdivided into three Subgroups(A) using Map system technique, (B) using Endodontic plugger and (C) using Rotary Lentuo spiral. All teeth were restored using stainless steel crowns. Teeth were evaluated radiographically regarding quality of obturation and presence of voids. Data was statistically analyzed using Chi- square test.

Result: Good results were observed with lentulospiral technique in terms of quality of obturation (optimum filling) followed by endodontic plugger technique and then map system with no significant difference $(\mathrm{P}=0.8)$. Voids were found in all subgroups with no significant difference between them. Significant difference was only between filled mesial and distal root canals of A1 and C1 subgroups ( $\mathrm{p}=0.016, \mathrm{P}=0.023$ ) respectively.

Conclusion: All techniques used for obturating primary root canals obturation showed good result regarding quality of obturation with no significant difference. Map syringe can be recommended as a technique of obturation as it is simple, easy to use, less threatening to the child.
\end{abstract}

Keywords: Pulpectomy; Primary Teeth; Obturation Technique; Zinc Oxide Eugenol; Iodoform

\section{Introduction}

Extensive decayed primary teeth that progresses to the dental pulp, remains a challenge in pediatric dental practice [1]. The main goal of pulp therapy in primary dentition is to retain a functional primary tooth for proper mastication, speech, swallowing. Also, for preservation of the space required for eruption of permanent teeth and prevention of bad psychological effects due to teeth loss [2,3].
Pulpectomy is a chemo mechanical preparation of the root canal by enlarging and shaping the canals to allow for adequate chemical debridement, while preserving the radicular anatomy [4-6]. pulpectomy is used for treatment of carious pulp exposure, and the radicular pulp has signs of hyperemia or necrosis [7].

The long-term viability and successful treatment of pulpectomized primary teeth are compromised if any restorative or end- 
odontic step is inadequate. Studies showed that, the success rate of pulpectomy may be significantly affected during the step of mixing the obturating material and during the obturation technique $[8,9]$.

Therefore, previous studies suggested several obturation techniques for filling pulpectomized primary teeth. Criteria of ideal obturation, root canals should be optimally filled without over or underfilling with no or minimal number of voids. Also the selected obturation method should be simple, easy to use and offer consistency $[10,11]$.

The success rated of obturated primary teeth is increased when the both the obturation materials and primary root are resorbed as well, to avoid any harmful effect on the permanent successor. Also, it should be resorbed if extended beyond the apex, antibacterial, radiopaque and not change the tooth color $[12,13]$. The most commonly used materials for filling pulp canals in primary teeth are zinc oxide eugenol, calcium hydroxide and iodoform -based pastes $[14,15]$.

Different techniques have been suggested for successful obturation of pulpectomized primary teeth. Root canal filling methods include endodontic pluggers, handheld or rotary lentulo-spiral, mechanical syringe, jiffy tube, tuberculin syringe, insulin syringe, pressure syringe, disposable injection technique, NaviTip, bidirectional spiral and pastinject [16].

A previous study was performed to compare various root primary canal obturation methods. Khubchandani., et al. (2017) [17] compared the efficiency of NaviTip syringe and lentulo spiral. Navi Tip group showed less number of voids while the lentulo spiral group showed more number of optimal fillings. Regarding apical seal, NaviTip showed better apical seal.

Pandranki., et al. (2017) [18] compared three obturation techniques: NaviTip, endodontic plugger and lentulospirals. The level of obturation and the presence of voids were evaluated radiographically. They found no significant difference between the three techniques to deliver Endoflas. Voids were observed in all the techniques used.

Nagarathna., et al. (2018) [19] performed a clinical study on 60 primary maxillary and mandibular molars. Teeth were divided according obturation technique into two groups (group 1: handheld lentulospiral technique and group 2: modified disposable syringe technique. Results showed that, quality of obturation after using the previous techniques has no significant difference. Also there was no significant difference between two groups regarding the presence of voids.

Chandrasekhar., et al. (2018) [20] carried out a clinical study on sixty-three pulpectomized primary teeth. Children enrolled in the study with age (5-9 years). Teeth classified into 4 groups, (group1) root canals obturated with endoflas using bidirectional spiral, (group2) incremental technique; (group3) past inject (group4) lentulo spiral. The effectiveness of the obturation technique was assessed radiographically. Results showed that obturation with lentulo spiral had the best result when compared with the others techniques.

Jose., et al. (2018) [21] evaluated 33 pulpectomized primary incisors filled with zinc oxide eugenol paste. According to the obturation technique, group 1 (lentulospiral technique), group 2 (insulin syringe technique) and group 3 (endodontic plugger technique). They concluded that, acceptable results were obtained with lentulospiral regarding length of obturation. Underfilling canals were observed more with insulin syringe technique although it had least number of voids.

Objective of this study was to evaluate radiographically different obturation techniques using pressure syringe (Map System), endodontic plugger and rotary lentulo-spiral in obturating root canals of primary molars using either zinc oxide eugenol or iodoform paste.

\section{Subjects and Methods}

This study was conducted on children who are healthy and cooperative with age range 4-7 years old who have at least one carious lower primary molar according to one or more of the following inclusion criteria [22]

- History of spontaneous pain.

- $\quad$ Presence of sinus tract.

- Periapical swelling or radiolucency.

- Excessive bleeding after removal of coronal pulp tissue.

- Presence of pus in pulp canal.

- Presence of radicular pathologic lesion.

- $\quad$ Presence of $\geq$ two thirds of root length. 


\section{Methods}

This study was performed in Department of Pediatric Dentistry, Faculty of Dentistry, Mansoura University, Egypt after obtaining approval from the institutional ethical Committee. Written informed consents from the parents were taken before starting the treatment.

One hundred and twenty carious primary molars were used for this study. Teeth were classified into two groups (60 each) according to the material used for obturation. Group I: obturated with zinc oxide eugenol paste (ZOE). Group 2: obturated with Iodoform paste. According to the obturation technique, each group was subdivided into three Subgroups (20 molars each)

- $\quad$ Subgroup A: using Map system technique.

- $\quad$ Subgroup B: using Endodontic plugger technique.

- $\quad$ Subgroup C: using Rotary Lentuo spiral technique.

\section{Clinical procedures}

Communication with children was established, then standardized baseline periapical radiographs were taken for all the selected teeth to exclude unsuitable teeth. Benzocaine $20 \%$ topical anesthesia gel was applied to dried mucosa for 2 minutes and then mandibular nerve block anesthesia was given, and the selected teeth were isolated using rubber dam. All caries was removed and access to the pulp was obtained by using a carbide bur. Mechanical preparation of root canals were performed using $\mathrm{H}$ files from size 8 to 35 with using apex locator and is followed by work length estimation. Frequent irrigation with sodium hypochlorite solution were performed. The canals were then dried by appropriately sized absorbent paper points and obturated as following:

- Subgroup A1 (Map system technique): Freshly prepared thick mix of ZOE paste was used. Then, appropriate size of Map syringe tip was selected which corresponding to the size of the canal. The syringe insert the prepared paste of ZOE into the canal. Lengths of the tip should be equal to the length of root canal minus $2 \mathrm{~mm}$. Additional increments were added until the canal was filled to the orifice. Wetted cotton pellet was used to pack the material into the canals.

- Subgroup B1 (Endodontic plugger technique): As in A1 subgroup, freshly prepared thick mix of ZOE paste was used. An appropriate size of endodontic plugger that corre- sponding to the size of the canal, with rubber stop was used to push ZOE into the canal. Length of endodontic plugger is adjusted to the root canal length minus $2 \mathrm{~mm}$.

- Subgroup C1 (Rotary lentulo spiral technique): Freshly prepared ZOE paste was inserted into the canals with rotary lentulo spiral. Appropriate size of lentulo-spiral was mounted to a low speed handpiece. It picks up the freshly prepared ZOE and inserted it into canals. This procedure was repeated 3-5 times until the canal orifices were visibly filled. Wet cotton pellet was used to push the remaining obturating material into the canals. Teeth in subgroups A2, B2 and C2 using iodoform paste were obturated as A1, B1 and C1. All root canals were prepared and filled by a single investigator.

Final restoration

After obturation of all root canals, Teeth were restored with amalgam or glass ionomer cement. In next visit, teeth were prepared for stainless steel crowns and cemented with glass ionomer cement.

\section{Evaluation}

Periapical radiographs were taken after obturation, for assessment. Two observers blindly assessed the quality of the filled root canals and presence of voids according to the following criteria ${ }^{(74):}$

- Underfilling (score 1): canal filling is shorter more than 2 $\mathrm{mm}$ from the apex.

- Optimal filling (score 2): canals filling material ending at the radiographic apex or up to $1 \mathrm{~mm}$ short of apex.

- Over filling (score 3): canals filling material extending outside the root apex.

- Voids: presence or absence of voids.

Data were statistically analyzed using Software (SPSS), Chi-square test was used to compare the difference of obturation quality between groups. Also, it determined the difference between subgroups regarding the presence or absence of voids. $(P$ value) was significant at $P<0.05$.

\section{Results}

For ZnOE group, Chi-square test revealed that, number of underfilled canals of A1 were statistically higher followed by B1 and $\mathrm{C} 1$ respectively. Meanwhile the number of overfilled canals of Io- 
doform group showed significantly higher difference in $\mathrm{C} 2$ when compared with B2 subgroup ( $\mathrm{P}=0.023)$. Table (1), (figure 2) Voids in obturation were found in both groups (Table 2) however, there

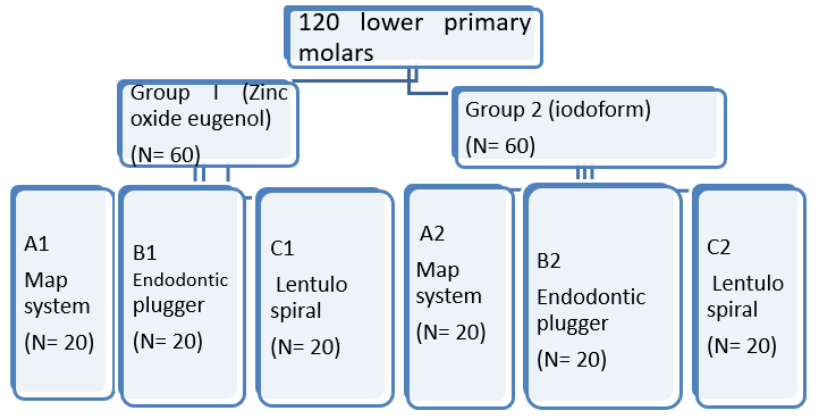

were no significant difference between subgroups. There was significant difference between filled mesial and distal root canals of A1 and C1 subgroups ( $p=0.016, P=0.023)$.

Figure 1: Schematic representation of teeth grouping.

\begin{tabular}{|c|c|c|c|c|c|c|c|c|c|c|}
\hline \multirow{2}{*}{$\begin{array}{l}\text { Quality of } \\
\text { obturation }\end{array}$} & \multicolumn{4}{|c|}{ ZOE (Group I) } & \multirow{2}{*}{$P$ value } & \multicolumn{4}{|c|}{ Iodoform (Group II) } & \multirow{2}{*}{$P$ value } \\
\hline & total & $\mathbf{A 1}$ & B1 & C1 & & total & A2 & B2 & $\mathrm{C} 2$ & \\
\hline Optimal & 111 & $\begin{array}{c}33 \\
(29.73 \%\end{array}$ & $\begin{array}{c}35 \\
(31.53 \%\end{array}$ & $\begin{array}{c}43 \\
(38.74 \%)\end{array}$ & 0.572 & 124 & $\begin{array}{c}38 \\
(30.65 \%)\end{array}$ & $\begin{array}{c}41 \\
(33.06 \%)\end{array}$ & $\begin{array}{c}45 \\
(36.29 \%)\end{array}$ & 0.8 \\
\hline Underfill & 94 & $\begin{array}{c}40 \\
(42.55 \%) \\
\mathrm{a} \\
\end{array}$ & $\begin{array}{c}37 \\
(39.36 \%) \\
b \\
\end{array}$ & $\begin{array}{c}17 \\
(18.09 \%) \\
a b\end{array}$ & $0.019 *$ & 74 & $\begin{array}{c}28 \\
(37.84 \%)\end{array}$ & $\begin{array}{c}32 \\
(43.24 \%)\end{array}$ & $\begin{array}{c}14 \\
(18.92 \%)\end{array}$ & 0.057 \\
\hline Overfill & 20 & $\begin{array}{c}4 \\
(20 \%)\end{array}$ & $\begin{array}{c}5 \\
(25 \%)\end{array}$ & $\begin{array}{c}11 \\
(55 \%)\end{array}$ & 0.219 & 34 & $\begin{array}{c}11 \\
(32.36 \%)\end{array}$ & $\begin{array}{c}4 \\
(11.76 \%) \mathrm{c}\end{array}$ & $\begin{array}{c}19 \\
(55.88 \%) \\
\text { c }\end{array}$ & $0.023^{*}$ \\
\hline
\end{tabular}

Table 1: Comparing quality of root canals obturation in the study

Similar letters mean significant difference between the subgroups in same group. The same symbols mean significant difference between the subgroups within the same raw.

\begin{tabular}{|c|c|c|c|c|c|c|c|c|c|c|}
\hline \multirow{3}{*}{\begin{tabular}{|l|}
$\begin{array}{l}\text { Voids } \\
\text { presence }\end{array}$ \\
Voids in \\
mesial \\
canal
\end{tabular}} & \multicolumn{4}{|c|}{ ZOE (Group I) } & \multirow{2}{*}{$\begin{array}{c}P \\
\text { value }\end{array}$} & \multicolumn{4}{|c|}{ Iodoform (Group II) } & \multirow[t]{2}{*}{$\begin{array}{c}P \\
\text { value }\end{array}$} \\
\hline & Total & A1 & B1 & $\mathrm{C} 1$ & & Total & A2 & B2 & $\mathrm{C} 2$ & \\
\hline & 54 & $\begin{array}{c}10 \\
(18.52 \%)\end{array}$ & $\begin{array}{c}21 \\
(38.89 \%)\end{array}$ & $\begin{array}{c}23 \\
(42.59 \%)\end{array}$ & 0.115 & 38 & $\begin{array}{c}11 \\
(28.95 \%)\end{array}$ & $\begin{array}{c}12 \\
(31.58 \%)\end{array}$ & $\begin{array}{c}15 \\
(39.47)\end{array}$ & 0.232 \\
\hline $\begin{array}{l}\text { Voids in } \\
\text { distal canal }\end{array}$ & 23 & $\begin{array}{c}9 \\
(39.13 \%)\end{array}$ & $\begin{array}{c}9 \\
(39.13 \%)\end{array}$ & $\begin{array}{c}5 \\
(21.74 \%)\end{array}$ & 0.578 & 29 & $\begin{array}{c}10 \\
(34.48 \%)\end{array}$ & $\begin{array}{c}6 \\
(20.69)\end{array}$ & $\begin{array}{c}13 \\
(44.83 \%)\end{array}$ & 0.859 \\
\hline$P$ value & & $0.016^{*}$ & 0.975 & $0.023^{*}$ & & & 0.523 & 0.057 & 0.372 & \\
\hline Total & 77 & $\begin{array}{c}19 \\
(24.68 \%)\end{array}$ & $\begin{array}{c}30 \\
(38.96 \%)\end{array}$ & $\begin{array}{c}28 \\
(36.36 \%)\end{array}$ & 0.355 & 67 & $\begin{array}{c}21 \\
(31.34 \%)\end{array}$ & $\begin{array}{c}18 \\
(26.87 \%)\end{array}$ & $\begin{array}{c}28 \\
(41.79 \%)\end{array}$ & 0.42 \\
\hline
\end{tabular}

Table 2: Distribution of voids in root canals of the study samples.

The same symbols mean significant difference between the subgroups within the same raw. 


\section{Discussion}

Pulpectomy of primary teeth is difficult due to the small, narrow, and torturous canals of these teeth, as well as the child's behavior. Therefore, successful treatment of primary root canals requires good analysis of pulp anatomy, determination of root length and hermetic seal of the canal to minimize the apical inflammation and possible damage to the permanent successor.

Accurate determination of apical foramen position is important for primary root canal obturation. In primary teeth with completed roots, the apical foramen position is near the anatomic root apex. As the root resorption progresses, the foramen may be coronal to the root apex of the primary tooth [23]. Therefore children enrolled in this study were selected with age range 4-7 years with mean age $(5.7 \pm 0.803)$.

Materials used for obturation should be resorbable so that, root resorption along with the filling does not interfere with eruption of permanent successor. In the present study, ZOE and iodoform paste were selected because of their availability and cost-effectiveness as compared to other filling material used for root canal obturations. Success of primary teeth pulpectomy depends on adaptability of filling material to the canal walls. Therefore, delivery system that carry the obturating material to the canals may affect the quality of obturation [24] In this study 3 different obturating technique were used to evaluate the quality of obturation and presence of voids.

In the present study, good results were observed with lentulospiral technique in terms of quality of obturation (optimum filling) followed by endodontic plugger subgroup (B) and then map system subgroup. There was no significant difference between them. This is supported by previous studies $[25,26]$ which reported that, lentulospiral presented best results when compared with endodontic file or syringe. Also, the result was in a line with Reddy., et al. (2015) [27] who showed no statistically significant differences between the pressure syringe and lentulospiral technique tested when apical seal, voids and extrusion were evaluated.

On the other hand, this study observed that, lentulospiral group had least number of under-filled canals which disagree with another study that reported lentulospiral showed a maximum number of underfilled canals [28]. Overfilling of primary root canals may be due to excessive pressure applied because of thick consis- tency of the filling material [29]. Vashista., et al. (2015) [30] supported our study as they concluded that, no significant difference was observed between pressure syringe or lentulospiral regarding the quality of obturation. Meanwhile, Nagaveni., et al. (2017) [31] suggested that canals obturated with rotary lentulospiral had the highest percentage of obturating volume followed by hand plugger technique and tuberculin syringe technique.

In the present study, voids were observed in all obturation techniques which is consistent with previous reports [32,33]. Map system (pressure syringe) group showed the least number of voids while the lentulo spiral group showed higher number with no significant difference and this agree with Khubchandani., et al. (2017) [34]. Voids in obturation using the pressure syringe (Map system) may be attributed to air entering the barrel while loading the material. Voids with lentulo spiral may be due to entrapping of air during the manipulation of the material or during the repeated removal and reinsertion of the spiral.

Voids in subgroup (B) (endodontic plugger) may be attributed to limited flexibility of endodontic pluggers. In addition, the possibility of large voids formation may be increased due to the movements of the plugger during paste application. The presence of voids may affect the quality of obturation during insertion of the paste into narrow and curved canals $[35,36]$. No significant difference was demonstrated between mesial and distal canals regarding voids formation for all subgroup. Meanwhile a significant difference was observed between subgroup A1 And C1

All teeth in this study were restored with glass ionomer cement or amalgam and stainless-steel crowns were cemented in the next visit. No follow-up was done; however, all children were asymptomatic in the subsequent visit where stainless-steel crown was placed. Clinical evaluation of obturation technique using Map System in primary molars is very limited, so there is a need for further research to evaluate this new system comparable to other techniques.

\section{Conclusions}

All techniques of primary root canals obturation used in this study showed good result regarding quality of obturation with no significant difference. Map syringe can be recommended as a technique of obturation as it is simple, easy to use, less threatening to the child. 


\section{Financial Support and Sponsorship}

Nil.

\section{Conflicts of Interest}

There are no conflicts of interest.

\section{Bibliography}

1. Guelmann M., et al. "The success of emergency pulpotomies in primary molars". International Journal of Paediatric Dentistry 24.3 (2002): 217-221.

2. Dummett CO Jr and Kopel HM. "Pediatric endodontics. In: Ingle JI, Bakl and LK, editors. Endodontics". $5^{\text {th }}$ ed. Hamilton: BC Decker Inc (2002): 861-902.

3. Ounsi HF., et al. "Endodontic considerations in pediatric dentistry: A clinical perspective". Int Dent South Afr 11 (2009): 4050.

4. American academy of pediatric dentistry. "Guideline on pulp therapy for primary and young permanent teeth". International Journal of Paediatric Dentistry 27.7 (2005): 130-134.

5. American academy of pediatric dentistry. "Guideline on pulp therapy for primary and young permanent teeth". International Journal of Paediatric Dentistry 31.6 (2009): 179-186.

6. Nagaraja S and Murthy BS. "CT evaluation of canal preparation using rotary and hand Ni-Ti instruments: An in vitro study". Journal of Conservative Dentistry 13.1 (2010): 16.

7. Moskovitz M and Sammara E Halan G. "Success rate of root canal treatment in primary molars". Journal of Dentistry 33 (2005): 41-47.

8. Mounce R. "Current Philosophies in Root Canal Obturation". Pennwell Publications (2008): 1-11.

9. Grover R., et al. "Clinical efficacy of various root canal obturation methods in primary teeth: comparative study". European Journal of Paediatric Dentistry 14.2 (2013): 104-108.

10. Guelmann M., et al. "Pulpectomies in primary incisors using three delivery systems; an in vitro study". International Journal of Clinical Pediatric Dentistry 28.4 (2004): 323-326.

11. Gutmann IL., et al. "Root Canal Obturation: An Update". Pennwell Publications (2010): 1-1.

12. Rifkin A. "A simple, effective, safe technique for the root canal treatment of abscessed primary teeth". Journal of Dentistry for Children 47 (1980): 435-441.
13. Pinkham JR. "Pediatric dentistry, 3rd ed, WB Saunders Company (1999).

14. Spedding RH. "Incomplete resorbtion of resorbable zinc oxide root canal filling in primary teeth:Report of two cases". Journal of Dentistry for Children 52 (1985): 214-216.

15. Kubota K., et al. "Root canal filling materials for primary teeth: A review of literature". Journal of Dentistry for Children 59 (1992): 225-227.

16. Mahajan N and Bansal A. "Various obturation methods used in deciduous teeth". International Journal of Medical and Dental Sciences 4 (2015): 708-713.

17. Khubchandani M., et al. "Comparative evaluation of different obturation techniques in primary molars: An in vivo study". The European Journal of General Dentistry 6 (2017): 42-47.

18. Pandranki J., et al. "A comparative assessment of different obturation techniques for obturation with endoflas in primary molars: An In vivo Study". Indian Journal of Dental Research 28.1 (2017): 44-48.

19. Nagarathna C., et al. "Primary molar pulpectomy using two different obturation techniques: A Clinical Study". The journal Contemporary Clinical Dentistry 9 (2018): 231-236.

20. Chandrasekhar S., et al. "A Comparative In vivo efficiency of three spiral techniques versus incremental technique in obturating primary teeth". Journal of Indian Society of Pedodontics and Preventive Dentistry 36 (2018): 71-75.

21. Jose A., et al. "Comparative Evaluation of three obturation techniques in Primary incisors using digital intraoral receptor and CBCT:an in vitro study". Clinical Oral Investigations (2018): 1-8.

22. Nagar p., et al. "An alternative obturating technique using insulin syringe delivery system to traditional reamer: An in-vivo study". Journal of Dentistry and Oral Biology 2.2 (2011): 7-19.

23. Ingle JI., et al. "Ingle's Endodontics 6: J Todd Milledge: Endodontic Therapy for Primary Teeth". $6^{\text {th }}$ ed. Hamilton, Ontario: BC Decker Inc; (2008)1400-1425.

24. Ramar K and Mungara J. "Clinical and radiographic evaluation of pulpectomies using three root canal filling materials: An in-vivo study". Journal of Indian Society of Pedodontics and Preventive Dentistry 28 (2010): 25-29. 
25. Sigurdsson A., et al. "Intracanal placement of calcium hydroxide: A comparison of techniques". Journal of Endodontics 18 (1992): 367-370.

26. Vashista K., et al. "Comparative evaluation of obturating techniques in primary teeth: in vivo study". International Journal of Clinical Pediatric Dentistry 8 (2015): 176-180.

27. Reddy PVR., et al. "Comparative Evaluation of Efficiency of Three Obturation Techniques for Primary Incisors-An In vivo Study". International Journal of Oral Health and Medical Research 2.2 (2015): 15-18.

28. Gandhi M., et al. "Clinical Assessment of Various Obturating Techniques for Primary Teeth: A Comparative Study". Journal of Clinical and Diagnostic Research 11 (2017): 48-51.

29. Subba Reddy VV and Shakunthala B. "Comparative assessment of three obturating techniques in primary molars: An in-vivo study". Endodontology 9 (1997): 13-16

30. Vashista K., et al. "Comparative Evaluation of Obturating Techniques in Primary Teeth: An In vivo study". International Journal of Clinical Pediatric Dentistry 8.3 (2015): 176-180.

31. Nagaveni NB., et al. "Volumetric Evaluation of Various Obturation Techniques in Primary Teeth Using Cone Beam Computed Tomography-An in vitro study". Journal of Indian Society of Pedodontics and Preventive Dentistry 35 (2017): 244-248.

32. Memarpour M., et al. "Comparison of different obturation techniques for primary molars by digital radiography". Pediatric Dentistry 35 (2013): 236.

33. Walia T., et al. "An in vitro comparison of three delivery techniques for obturation of root canals in primary molars". European Archives of Paediatric Dentistry 18 (2017): 17-23.

34. Khubchandani M., et al. "Comparative evaluation of different obturation techniques in primary molars: An in vivo study". The European Journal of General Dentistry 6 (2017): 42-47.

35. Kumar S., et al. "Comparison of obturation techniques using three delivery systems: An in vitro study". Journal of Dental Sciences 1 (2016): 13-17.

36. Sijeria P., et al. "Evaluation of Root Canal Filling in Primary Teeth by Volumetric Analysis: An In vitro Study". International Journal of Clinical Pediatric Dentistry 11.5 (2018): 386-392.

\section{Assets from publication with us}

- Prompt Acknowledgement after receiving the article

- Thorough Double blinded peer review

- Rapid Publication

- Issue of Publication Certificate

- High visibility of your Published work

Website: www.actascientific.com/

Submit Article: www.actascientific.com/submission.php

Email us: editor@actascientific.com

Contact us: +919182824667 